\title{
Quantitative electroencephalography power and coherence measurements in the diagnosis of mild and moderate Alzheimer's disease
}

\author{
Lineu Corrêa Fonseca', Gloria Maria Almeida Souza Tedrus', \\ Larissa Rodrigues Prandi², Ana Carolina Amaral de Andrade ${ }^{3}$
}

\begin{abstract}
Objective: To evaluate the contribution of quantitative electroencephalographic (qEEG) analyses in the diagnosis of Alzheimer's disease (AD). Method: Thirty-five patients from the Neurology Outpatients Clinic of PUC-Campinas, diagnosed with AD according to the NINCDS/ADRDA were evaluated, and compared with a control group consisting of 30 individuals with no cognitive deficit. The procedures consisted of clinical-neurological, cognitive and behavioral analyses and the qEEG (absolute power and coherence). Results: The AD group presented greater absolute power values in the delta and theta bands, greater theta/alpha indices and less frontal alpha and beta coherence. Logistic multiple regression models were constructed and those only showing variations in the qEEG (frontal alpha coherence and left frontal absolute theta power) showed an accuracy classification (72.3\%) below that obtained in the mini-mental state examination (93\%). Conclusion: The study of coherence and power in the GEEG showed a relatively limited accuracy with respect to its application in routine clinical practice.
\end{abstract}

Key words: dementia, Alzheimer's disease, electroencephalography, EEG, coherence.

Medidas de coerência e de potência absoluta no eletrencefalograma quantitativo no diagnóstico da doença de Alzheimer

\section{RESUMO}

Objetivo: Avaliar a contribuição das análises quantitativas do eletroencefalograma (qEEG) no diagnóstico da doença de Alzheimer (DA). Método: Foram avaliados 35 pacientes do ambulatório de Neurologia Clínica da PUC-Campinas, com o diagnóstico de DA segundo o NINCDS/ADRDA e comparados a 30 indivíduos, sem déficit cognitivo, de grupo controle. Os procedimentos foram avaliação clínico-neurológica, cognitiva e comportamental e EEGq (potência absoluta e coerência). Resultados: O grupo DA apresentou maiores potências absolutas nas faixas delta e teta, maiores índices teta/alfa e menor coerência alfa e beta frontal. Foram construídos modelos de regressão múltipla

Correspondence Lineu Corrêa Fonseca

Rua Sebastião de Souza 205 / 122 13013-910 Campinas SP - Brasil E-mail: lineu.fonseca@uol.com.br

\section{Support}

This work was in part supported by FAPIC / Reitoria - PUC - Campinas and PIBIQ/CNPq - PUC - Campinas

Received 8 September 2010 Received in final form 9 December 2010 Accepted 16 December 2010 logística e aquele que contou apenas com variáveis do EEGq (coerência alfa frontal e potência absoluta teta frontal esquerda) teve acurácia de classificação (72,3\%), inferior à obtida com o mini-exame do estado mental (93\%). Conclusão: $O$ estudo de coerência e potência no qEEG tem acurácia relativamente limitada no sentido de aplicação prática clínica rotineira.

Palavras-chave: demência, doença de Alzheimer, eletroencefalografia, EEG, coerência, potência absoluta.

'Professor of Neurology, Faculdade de Medicina da Pontifícia Universidade Católica de Campinas (PUC-Campinas), Campinas SP, Brazil; ${ }^{2}$ Placement scholarship student (FAPIC)/Reitoria, PUC-Campinas; ${ }^{3}$ Placement Scholarship Student PIBIQ/CNPq, PUC-Campinas. 
Dementia is one of the commonest disorders in the aged and is clinically diagnosed based on international consensus.

Alzheimer's disease (AD), the most common cause of dementia, lacks viable markers allowing for its diagnosis, and the current gold standard consists of the clinical criteria proposed by the NINCDS-ADRDA ${ }^{1}$ and by the DSM-IV ${ }^{2}$.

In clinical-pathological series, the NINCDS-ADRDA criteria ${ }^{1}$ show a diagnostic accuracy of $80-95 \%{ }^{3}$, and thus other procedures with diagnostic value for Alzheimer's disease require accuracy increments above these levels.

Various neuroimaging, biochemical and genetic methods have been investigated for the diagnosis of AD, without characterizing any specific markers ${ }^{4}$.

On examining electrical brain activity, the electroencephalogram (EEG) is a functional exam useful in evaluating cognitive disturbances, and can be of use in diagnosing patients with cognitive deficits, especially when diagnostic doubts exist after the initial clinical procedures 5 .

In addition to analyzing the trace, the development of the digital EEG allows one to carry out various types of quantitative analyses ( $\mathrm{EEEG}$ ), amongst which the most used are the analysis of frequency and coherence. In the analysis of frequency, the powers of various frequency bands are calculated, which constitute the electrical brain activity, whereas in the analysis of coherence, the relationship of the EEG between two regions is studied, making it possible to evaluate the connectivity between them and obtain information about functional interactions between neural networks represented on the cortex ${ }^{6}$. Methods have also been researched for the evaluation of patients with mild cognitive disorders or $\mathrm{AD}$, applying other quantitative approaches, such as the analysis of the sources of cortical rhythms ${ }^{7}$, non-linear time series analyses ${ }^{8}$, and during functional activities ${ }^{9}$.

Various research projects have considered the possible contribution of EEG and qEEG in the diagnosis of the start of $\mathrm{AD}$ and in the prediction of the evolution of a mild cognitive disturbance to dementia.

In a recent review, Jelic et al. ${ }^{10}$, concluded that although various studies had presented elevated accuracy indices for the use of EEG and qEEG in the diagnosis of $A D$, the evidences were still not sufficient for its use in the initial evaluation of these patients.

Considering that EEG is a widely available, low cost and non-invasive procedure, it is of interest to research a combination of quantitative approaches in order to evaluate its use in the diagnosis of $\mathrm{AD}$.

The use of the frequencies and coherence as analytical variables was applied together in some studies with patients showing cognitive disorders, with promising results ${ }^{9,11}$.
The objective of the present work was to comparatively study patients with AD (mild and moderate) and healthy controls, using a joint analysis of the absolute powers, including the theta/alpha index and that of the coherences, using techniques available in the majority of EEG equipments, and evaluate the value of the measurements from qEEG in the diagnosis of AD.

\section{METHOD}

\section{Participants}

Thirty-five patients were included, all attending the Outpatient's Department of the Neurology Clinic of the Celso Pierro General \& Maternity Hospital - PUC/ Campinas, and all with dementia according to the Diagnostic and Statistical Manual of Mental Disorders $(\mathrm{DSM} \text { IV }, 1994)^{2}$ and diagnosis of AD (slight or moderate stages) according to the criteria of the NINCDS/ADRDA (National Institute of Neurological and Communicative Disorders and Stroke and Alzheimer's disease) $)^{1}$. A control group was also set up, including 30 subjects with no history of cognitive decline or previous neurological or psychiatric disorders and of similar gender and age range. These were also submitted to the EEG and the same clinical-neurological assessments and cognitive tests as the AD patients.

The criteria used for exclusion were: co-morbidity with a significant reduction in life expectancy; treatment with acetylcholinesterase inhibitors or any other modulator of cognitive function; treatment with any other drugs with the potential to alter cognitive function, such as benzodiazepines and anti-psychotic drugs; and a score lower than 4 on the Hachinski scale in order to minimize the possibility of vascular disease and focal lesions in the neuroimaging exams.

\section{Procedures}

The patients were submitted to the following procedures: clinical-neurological evaluation, general laboratory exams, and computed tomography or magnetic resonance imaging to eliminate other causes of the dementia; the CERAD (Consortium to Establish a Registry for Alzheimer's Disease) neuropsychological battery; the Pfeffer questionnaire; and the Clinical Dementia Rating (CDR).

The cognitive and behavioral evaluations followed the recommendations of the National Consensus ${ }^{12}$. Application of the CERAD neuropsychological battery and the EEG were carried out on the same day.

The CERAD neuropsychological battery considers items for the diagnosis of dementia in the aged, and includes the items: MMSE, verbal fluency, abridged Boston Naming Test, word list memory with repetition, constructional praxis, recall and recognition of word list and 
recall of constructional praxis. The scores correspond to the correct answers for all the items.

The Pfeffer questionnaire for functional activity evaluates the interference of the dementia in daily activities, scoring according to the decline in performance quality in these activities.

The CDR was used to classify the phase of dementia according to a scoring system.

\section{Electroencephalogram}

This registers brain electrical activity with the objective of allowing for its analysis. The EEG was recorded with a resolution of 12 bits, 0.5 and $35 \mathrm{~Hz}$ filters and 200 samples per second, using the Braintech 3.0 equipment (EMSA Equipamentos Médicos) in the Electroencephalography Center. Impedance was maintained below $10 \mathrm{k} \Omega$. The exam was carried out with the individual at rest, in a silent environment with low intensity lighting. The electrodes were placed according to the International 10-20 System, with the use of an additional two electrodes placed $1 \mathrm{~cm}$ below (left side) and above (right side) the external angle of the eyelid, with the objective of evaluating eye movements. The inter-connected ear lobe electrodes served as the reference. The data were recorded during five periods, alternating 2-min resting periods with the eyes closed with 2-min awake periods with the eyes open.

For the quantitative EEG analyses, 18 to 26 epochs free of artifacts and without paroxysms were selected while awake and resting (eyes closed), each lasting 2.56s. The author (LCF) had no information on the clinical diagnosis of the individuals when selecting the epochs. After applying the Fast Fourier Transform, the absolute powers were studied in the following frequency bands: delta (up to $3.9 \mathrm{~Hz}$ ), theta (4.9 to $7.8 \mathrm{~Hz}$ ), alpha (8.2 to $12.5 \mathrm{~Hz}$ ) and beta (12.9 to $36.3 \mathrm{~Hz}$ ).

To obtain a normal distribution of the data, the values for absolute power were substituted by their logarithms. The absolute power was analyzed for the traditional frequency bands and for all the individual electrode positions with the exception of Fp1, Fp2, F7 and F8, in order to avoid ocular artifacts.

To analyze for coherence, this was defined as:

$$
\operatorname{Coh}_{x y}(f)=\left[R_{x y}(f)\right]^{2}=\frac{\left[G_{x y}(f)\right]^{2}}{G_{x x}(f)\left(G_{y y}(f)\right.}
$$

where $\mathrm{G}_{\mathrm{xy}}(f)$ denotes the spectral density of the cross-power and $\mathrm{G}_{\mathrm{xx}}(f)$ and $\mathrm{G}_{\mathrm{yy}}(f)$ are the respective spectral densities of the power. The inter-hemispheric coherences between the following pairs of homologue electrodes were calculated: frontal left-right (F3-F4); mid temporal left-right (T3-T4) and occipital left-right (O1O2). For the intra-hemispheric coherences, the coherences between the frontal-occipital, center-parietal and mid temporal-posterior pairs were measured, both to the left (F3-O1, C3-P3 and T3-T5) and to the right (F4-O2, C4-P4 and T4-T6). These measurements were taken for each of the 4 bands (delta, theta, alpha and beta).

Considering that the coherence measurements depend on the distance between the electrodes, coherences between electrodes with different distances were not compared, and only equivalent coherences were compared between the AD and control groups.

\section{Data analysis}

The Statistical Packages for Social Sciences (SPSS 10.0.1) was used for the data analysis, applying parametric and non-parametric tests according to the data distribution as assessed by the Wilk-Shapiro test and an analysis of the histogram. All the tests were two -tailed and the level of significance was fixed at $\mathrm{p} \leq 0.05$. Logistic binary regression models were constructed with $\mathrm{p}<0.05$.

The patients with AD were initially compared with the controls with respect to the socio-demographic data, the results of the Mini-Mental State Examination (MMSE), means of the logarithms of the absolute powers at the various electrode positions, and also the measurements of intra-hemispheric and inter-hemispheric coherences in the 4 frequency bands.

In the logistic regression analysis for the diagnosis of $A D$, variables with $\mathrm{p}<0.10$ in the comparison between the AD and control groups were included, in a search for statistically significant models that allowed for the calculation of accuracy in the discrimination between the groups.

\section{Ethical aspects}

The Ethics Commission for Research with Human Beings approved the project, and the subjects signed informed consent forms.

\section{RESULTS}

\section{Clinical aspects}

Table 1 shows the socio-demographic data and the results for the Mini-Mental State Examination for the 35 patients in the AD group and the 30 controls. There was no significant difference between the groups with respect to age and gender, although the AD group showed a shorter scholastic period than the control group ( $\mathrm{t}$ test, $\mathrm{p}<0.05$ ). The scores in the MMSE were significantly lower for the AD group. Twenty three patients in the AD group showed a mild form of the disease and 12 moderate. 
Table 1. Socio-demographic data and results of the Mini-Mental State Examination in patients with $\mathrm{AD}$ and the control group.

\begin{tabular}{lccc}
\hline & Alzheimer & CG & \\
& $\mathrm{N}=35$ & $\mathrm{~N}=30$ & P value \\
\hline Age (yrs) & $73.63(6.50)$ & $71.60(4.26)$ & $0.149^{1}$ \\
Gender (male/female) & $12 / 23$ & $7 / 23$ & $0.333^{2}$ \\
Education (yrs) & $3.21(3.16)$ & $5.58(4.84)$ & $0.026^{3}$ \\
Mini-Mental State Examination & $17.06(4.44)$ & $26.80(2.09)$ & $0.000^{1}$ \\
\hline
\end{tabular}

When mean values are shown, the standard deviations (SD) are given in parentheses. ${ }^{1} \mathrm{t}$ test; ${ }^{2}$ chi-squared test; ${ }^{3}$ Mann-Whitney U test, CG: control group.

Table 2. Means (SD) of the logarithms of the absolute powers in the delta and theta bands for the various positions of the electrodes in the $A D$ and control groups.

\begin{tabular}{|c|c|c|c|c|c|c|}
\hline \multirow[b]{2}{*}{ Electrode } & \multicolumn{3}{|c|}{ Delta power } & \multicolumn{3}{|c|}{ Theta power } \\
\hline & $A D$ & CG & $P$ value & $A D$ & CG & $P$ value \\
\hline $\mathrm{T} 3$ & 29.29 (6.78) & $27.25(5.81)$ & 0.201 & 33.76 (9.85) & $29.79(9.28)$ & 0.101 \\
\hline $\mathrm{T} 5$ & $29.85(7.08)$ & $26.60(5.92)$ & 0.051 & $37.30(11.05)$ & $31.69(11.42)$ & $0.049^{*}$ \\
\hline F3 & $32.95(6.15)$ & $30.41(6.02)$ & 0.099 & 38.95 (9.36) & $33.08(9.02)$ & $0.013^{*}$ \\
\hline $\mathrm{C} 3$ & $32.03(6.76)$ & $29.78(5.31)$ & 0.146 & 39.37 (10.76) & 33.79 (9.36) & $0.031^{*}$ \\
\hline P3 & $33.42(7.10)$ & $30.48 \pm 5.98$ & 0.101 & 41.31 (11.48) & 35.25 (10.68) & $0.032^{*}$ \\
\hline 01 & $32.31(7.12)$ & $29.15(6.35)$ & 0.065 & $40.72(11.70)$ & $34.28(11.85)$ & $0.031^{*}$ \\
\hline $\mathrm{T} 4$ & $29.03(6.83)$ & $27.11(6.18)$ & 0.243 & $33.24(10.23)$ & $29.52(9.75)$ & 0.140 \\
\hline T6 & $29.94(6.83)$ & $27.19(5.53)$ & 0.091 & $36.92(11.51)$ & $31.38(11.17)$ & 0.054 \\
\hline $\mathrm{F} 4$ & 33.37 (6.26) & $30.87(5.68)$ & 0.099 & $39.20(9.75)$ & $33.97(9.30)$ & $0.032^{*}$ \\
\hline C4 & 32.47 (7.24) & $30.77(5.68)$ & 0.301 & 39.55 (10.92) & $34.62(10.04)$ & 0.064 \\
\hline P4 & $33.33(7.33)$ & $30.97(5.06)$ & 0.143 & 40.99 (11.59) & $35.54(11.11)$ & 0.059 \\
\hline $\mathrm{O} 2$ & 33.52 (6.72) & $30.33(5.99)$ & $0.049^{*}$ & $40.94(12.14)$ & 34.39 (12.04) & $0.033^{*}$ \\
\hline F0 & $33.97(6.20)$ & $30.82(5.75)$ & $0.039^{*}$ & $40.09(9.52)$ & $34.52(9.58)$ & $0.022^{*}$ \\
\hline $\mathrm{CO}$ & $33.84(6.84)$ & $31.84(5.79)$ & 0.212 & $40.86(10.95)$ & 34.93 (9.64) & $0.025^{*}$ \\
\hline PO & $34.42(7.28)$ & $32.29(5.30)$ & 0.189 & $42.04(11.29$ & $36.44(10.44)$ & $0.043^{*}$ \\
\hline
\end{tabular}

${ }^{*}$ t test, $\mathrm{p}<0.05$; AD: Alzheimer group; CG: control group.

\section{Quantitative EEG}

Table 2 shows the means of the logarithms for the absolute powers in the delta and theta frequency bands and the values for $\mathrm{P}$, in the comparison between the $\mathrm{AD}$ group and the controls.

It can be seen that the powers in the theta band were greater in the $\mathrm{AD}$ group than in the CG group, with statistical significance for all the electrodes studied except for T3, T4 and T6.

With respect to the delta band, the powers were only greater in a statistically significant way for the $\mathrm{AD}$ group at electrodes $\mathrm{O} 2, \mathrm{C} 0$ and $\mathrm{F} 0$.

There was no significant difference between the AD group and the controls for the alpha and beta bands.

The theta / alpha indices in Table 3 show that they were significantly greater for the $\mathrm{AD}$ group at all the electrodes studied except T3.

With respect to coherence, a statistically significant difference was only found between the $\mathrm{AD}$ group and the controls for the frontal (F3-F4), inter-hemispheric (alpha and beta bands) and inter-occipital (O1-O2) beta coherences (Table 4).

\section{Logistic multiple regression in the classification between the Alzheimer and control groups}

Table 5 shows the regression models for the classification between $\mathrm{AD}$ and the controls using the MMSE (model 1) and the qEEG variables - F3 theta power and F3-F4 alpha coherence (model 2). The accuracy of the model that only included the QEEG variables was $72.3 \%$, with a sensitivity of $71.42 \%$ and specificity of $73.3 \%$, lower than the accuracy of the MMSE. The qEEG variables failed to add accuracy to the MMSE in diagnosing $\mathrm{AD}$. The theta/alpha indices did not enter the regression equations in a significant way. 
Table 3. Means (SD) for the theta/alpha indices for the various positions of the electrodes in the AD and control groups.

\begin{tabular}{cccc}
\hline \multicolumn{4}{c}{ Theta / alpha indices } \\
\hline Electrode & AD & CG & P value \\
\hline T3 & $0.922(0.192)$ & $0.841(0.138)$ & 0.058 \\
T5 & $0.914(0.215)$ & $0.801(0.127)$ & $0.014^{*}$ \\
F3 & $0.944(0.170)$ & $0.850(0.128)$ & $0.016^{*}$ \\
C3 & $0.900(0.175)$ & $0.820(0.122)$ & $0.040^{*}$ \\
P3 & $0.889(0.174)$ & $0.793(0.110)$ & $0.012^{*}$ \\
O1 & $0.901(0.210)$ & $0.779(0.135)$ & $0.008^{*}$ \\
T4 & $0.913(0.188)$ & $0.807(0.128)$ & $0.011^{*}$ \\
T6 & $0.896(0.211)$ & $0.780(0.141)$ & $0.013^{*}$ \\
F4 & $0.941(0.166)$ & $0.844(0.104)$ & $0.008^{*}$ \\
C4 & $0.903(0.181)$ & $0.816(0.113)$ & $0.026^{*}$ \\
P4 & $0.884(0.184)$ & $0.788(0.115)$ & $0.016^{*}$ \\
O2 & $0.897(0.211)$ & $0.765(0.135)$ & $0.005^{*}$ \\
F0 & $0.970(0.180)$ & $0.863(0.131)$ & $0.009^{*}$ \\
C0 & $0.905(0.1630$ & $0.804(0.110)$ & $0.005^{*}$ \\
P0 & $0.895(0.169)$ & $0.817(0.169)$ & $0.033^{*}$ \\
\hline
\end{tabular}

${ }^{*}$ test, $\mathrm{p}<0.05$; $\mathrm{AD}$ : Alzheimer group; $\mathrm{CG}$ : control group.

\section{DISCUSSION}

In studies on $\mathrm{AD}$ using analyses of EEG frequencies, an increase in activity of the theta band has been found, and during evolution of the disease, this is associated with an increase in the delta activity and a decrease in the alpha and beta bands ${ }^{13}$. The increase in theta activity and reduction in alpha activity can be accompanied by calculating the theta/alpha index.

In the present casuistry, the finding of an increase in theta power, and to a lesser extent of the delta band, is similar to that reported in the literature ${ }^{13-15}$. No significant decreases in the alpha and beta powers were found, probably because the greater part of the patients was in the mild stage of AD. Nevertheless, the AD group showed theta/alpha indices significantly higher than those of CG, indicating behavioral differences with respect to the alpha and theta powers.

The EEG slowing of AD, observed in the analysis of the frequencies appeared to depend on the cholinergic deficit, since there was a neocortical disconnection with structural or functional rupture of the long cortico-cortical tracts ${ }^{16}$.

In the analysis of coherence in $\mathrm{AD}$, the most frequent finding is a reduction in the alpha and beta bands ${ }^{16-19}$.

Table 4. Means (SD) for the coherences in the alpha and beta bands for the AD and control groups and the respective values for $\mathrm{p}$ in the comparison.

\begin{tabular}{|c|c|c|c|c|c|c|}
\hline \multirow[b]{2}{*}{ Electrodes } & \multicolumn{3}{|c|}{ Alpha coherences } & \multicolumn{3}{|c|}{ Beta coherences } \\
\hline & $A D$ & CG & $\mathrm{p}$ & $A D$ & CG & $\mathrm{p}$ \\
\hline $\mathrm{T} 3-\mathrm{T} 4$ & $0.41(0.06)$ & $0.41(0.07)$ & 0.927 & $0.37(0.04)$ & $0.37(0.03)$ & 0.865 \\
\hline F3-F4 & $0.56(0.106)$ & $0.62(0.11)$ & $0.038^{*}$ & $0.450(0.07)$ & $0.49(0.074)$ & $0.017^{*}$ \\
\hline O1-O2 & $0.59(0.157)$ & $0.54(0.12)$ & 0.219 & $0.55(0.15)$ & $0.48(0.12)$ & $0.048^{*}$ \\
\hline T3-T5 & $0.65(0.095)$ & $0.65(0.10)$ & 0.852 & $0.58(0.10)$ & $0.67(0.09)$ & 0.338 \\
\hline F3-O1 & $0.44(0.069)$ & $0.44(0.06)$ & 0.832 & $0.39(0.04)$ & $0.40(0.04)$ & 0.886 \\
\hline C3-P3 & $0.80(0.073)$ & $0.78(0.11)$ & 0.452 & $0.72(0.08)$ & $0.685(0.10)$ & 0.108 \\
\hline T4-T6 & $0.62(0.083)$ & $0.63(0.09)$ & 0.458 & $0.57(0.08)$ & $0.57(0.09)$ & 0.825 \\
\hline $\mathrm{F} 4-\mathrm{O} 2$ & $0.44(0.071)$ & $0.45(0.06)$ & 0.419 & $0.39(0.04)$ & $0.39(0.04)$ & 0.934 \\
\hline C4-P4 & $0.80(0.082)$ & $0.79(0.08)$ & 0.961 & $0.73(0.10)$ & $0.73(0.08)$ & 0.181 \\
\hline
\end{tabular}

*t test, $\mathrm{p}<0.05 ; \mathrm{AD}$ : Alzheimer group; CG: control group.

Table 5. Regression models for the classification between Alzheimer's disease and the controls: qEEG and MiniMental State Examination and accuracy

\begin{tabular}{lcc}
\hline Variable & Model 1 & Model 2 \\
\hline MMSE & $.486(.340-.693) ; P=0.0001$ & \\
F3-F4 alpha coherence & - & $.002(.000-.450) ; P=0.024$ \\
F3 theta power & - & $1.087(1.019-1.160)$ \\
Classification accuracy of the model & $92.3 \%$ & $72.3 \%$ \\
\hline
\end{tabular}

MMSE: mini-mental state examination. Values in the table are the odds ratio, the interval of confidence at $95 \%$ is in parenthesis, and $P$ value. 
Similarly, in the present study, the significant alterations in coherence occurred essentially in the alpha and beta bands between the frontal (F3-F4) and occipital (O1-O2) regions.

The analysis of coherence assesses relationships between regions, that is, the connectivity between cortical areas. The reduction in the alpha and beta coherences suggests functional disconnections between cortical areas and can be interpreted as a neocortical "disconnection syndrome" in $\mathrm{AD}^{16}$.

One probable factor affecting the genesis of these alterations could be that the basal forebrain neurons are severely affected in AD, leading to a brain cholinergic deficit which, for its part, could lead to the genesis of cognitive symptoms as also to EEG slowing, and also to a decrease in coherence ${ }^{20}$.

The alterations found in the qEEG in the present research can be considered characteristic of AD.

\section{The QEEG in the diagnosis of Alzheimer's disease}

A visual analysis of the EEG can be used in the evaluation of cognitive disturbances, particularly when diagnostic doubts remain after the basic clinical procedures ${ }^{5,21}$.

A normal EEG is of reduced value in the assessment of cognitive disturbances, since it can occur in 4.8 to $14 \%$ of $\mathrm{AD}$ cases, but an abnormal EEG increases the possibility of dementia ${ }^{10}$.

With respect to the qEEG, much research has been carried out aimed at evaluating its diagnostic value in AD. These studies show considerable diversity in the methods for both the selection and size of the casuistry of the $\mathrm{AD}$ group and $\mathrm{CG}$, and in the diagnostic criteria, data collection and approach used in the qEEG and in the statistical methods applied. The results for accuracy, sensibility and specificity varied widely between the studies ${ }^{10}$.

In the present research the analyses of frequency and coherence were studied together with the aim of attaining greater diagnostic accuracy, considering that these methods evaluate different characteristics of the electrical brain activity and are probably related to differences in physio-pathological mechanisms.

In the regression, one analytical variable of power (absolute frontal theta) and another of coherence (frontal alpha coherence, F3-F4), entered the equation, corresponding to the nucleus of alterations occurring in the qEEG in $A D$, the increase in activity of theta and decrease in frontal alpha coherence. The theta/alpha indices did not enter the equation in a significant way, suggesting a greater importance of the increase in theta activity in discriminating between AD and CG.

The sensitivity and specificity obtained by the qEEG in the present study were respectively $71.4 \%$ and $73.3 \%$, within the ranges found in the literature, which varied from 24 to $94 \%$ for sensitivity in the different studies ${ }^{22-25}$, and from 73 to $100 \%$ for specificity $17,23,26,27$.

In the studies assessing power and coherence together in the classification of the AD and control groups, the accuracy was between 77 and $89 \% 28,29$.

The great differences in accuracy found in the literature probably depended on various factors. Greater accuracy in the classification between the AD and control groups could be due, for example, to series for the AD group with the inclusion of advanced cases, control groups without the co-morbidities commonly found in a clinic, and the use of more adequate statistical methods.

In the current study, the relatively lower values for sensitivity could, in part, be due to the inclusion of a majority of patients with mild $\mathrm{AD}$ and of individuals in the control group with various co-morbidities, so long as they did not potentially interfere with life expectancy. Also, the assessment of the EEG and selection of epochs for analysis was done in a blind way, with a possible reduction in biases in the results.

With respect to the results of the $\mathrm{qEEG}$, considering the different assessment methods, it is worth emphasizing the research of Lehmann et al. ${ }^{30}$ who, in the same casuistry, compared different variables of the qEEG, and also different classification methods between the AD patients and controls, considering 197 patients and 45 controls. The EEG was carried out at rest with the eyes closed and absolute and relative powers were assessed with spectral distribution and measures of spatial synchronization. These authors verified that modern computer-intensive classification algorithms such as random forests, support vector machines and neural networks, showed slightly better performance than the classical classification algorithms (component linear discriminant analysis, principal component logistic regressions). In the discrimination between mild $\mathrm{AD}$ and the controls, there was a sensitivity of $85 \%$ and specificity of $78 \%$.

In the present study, the EEG variables that entered the model in a significant way were both of the frontal regions, the frontal theta absolute power and the alpha coherence. Based on these variables, the model showed an accuracy of $72.3 \%$, which is insufficient for clinical application, as has been observed with other qEEG methods $7,10,28,30$.

In a recent, ample review, Jelic et al..$^{10}$ concluded that there was no qEEG measurement that could be considered as a marker of dementia and of AD in particular. Thus the use of qEEG in the diagnosis of Alzheimer must remain restricted to situations in which diagnostic doubts remain after the initial assessments.

However, perspectives exist for the development of uniform standards in multicentric prospective studies, 
searching to assess the diagnostic increment of EEG and qEEG with respect to multimodal assessment batteries in the diagnosis of $\mathrm{AD}^{10}$.

\section{REFERENCES}

1. McKhann G, Drachman D, Folstein M, et al. Clinical diagnosis of Alzheimer's disease: report of the NINCDS-ADRDA Work Group under the auspices of Department of Healthy and Human Services Task force on Alzheimer's disease. Neurology 1984;34:939-944.

2. American Psychiatric Association. Diagnostic and Statistical Manual of Mental Disorders. $4^{\text {th }}$ edition. Washington D.C. American Psychiatric Association, 1994.

3. Hogervorst E, Barnetson L, Jobst KA, Nagy Z, Combrinck M, Smith AD. Diagnosing dementia: interrater reliability assessment and accuracy of NINCDSADRDA criteria versus CERAD histopathological criteria for Alzheimer's disease. Dement Geriatr Cogn Disord 2000;11:107-113.

4. Dubois B, Feldman HH, Jacova C, et al. Research criteria for the diagnosis of Alzheimer's disease: revising the NINCDS-ADRDA criteria. Lancet Neurol 2008;7:668-670

5. Claus JJ, Strijers RL, Jonkman EJ, et al. The diagnostic value of electroencephalography in mild senile Alzheimer's disease. Clin Neurophysiol 1999;110:825-832.

6. Hogan MJ, Swanwick GRJ, Kaiser J, Rowan M, Lawlor B. Memory-related EEG power and coherence reduction in mild Alzheimer's disease. Int J Psychophysiol 2003:49:147-163.

7. Babiloni C, Cassetta E, Binetti G, et al. Resting EEG sources correlate with attentional span in mild cognitive impairment and Alzheimer's disease. Eur J Neurosci 2007;25:3742-3757

8. Jeong J. EEG dynamics in patients with Alzheimer disease. Clin Neurophysiol 2004;115:1490-1505.

9. van der Hiele K, Vein AA, Reijntjes RH, et al. EEG correlates in the spectrum of cognitive decline. Clin Neurophysiol 2007;118:1931-1939.

10. Jelic V, Kowalski J. Evidence-based evaluation of diagnostic accuracy of resting EEG in dementia and mild cognitive impairment. Clin EEG Neurosci 2009;40:129-142

11. Rossini PM, Del Percio C, Pasqualetti P, et al. Conversion from mild cognitive impairment to Alzheimer's disease is predicted by sources and coherence of brain electroencephalography rhythms. Neuroscience 2006;143:793-803.

12. Nitrini $R$, Caramelli $P$, Bottino CMC, Damasceno BP, Anghinah R. Diagnóstico de doença de Alzheimer no Brasil. Avaliação cognitiva e funcional. Recomendações do Departamento Científico de Neurologia cognitiva e do Envelhecimento da Academia Brasileira de Neurologia. Arq Neuropsiquiatr 2005;63:720-727

13. Miyauchi T, Hagimoto H, Ishii M, Tanaka K, Kajwara A, Kosaka K. Quantitative EEG in patients with presenile and senile dementia of the Alzheimer type. Acta Neurol Scand 1994;89:56-64.

14. Chiaramonti R, Muscas GC, Paganini M, et al. Correlations of topographical EEG features with clinical severity in mild and moderate dementia of Alzheimer type. Neuropsycobiology 1997;36:153-158.
15. Deslandes A, Ribeiro P, Veiga H, Cagy M, Fiszman A, Piedade RAM. Quantitative electroencephalography ( $\mathrm{qEEG}$ ) to discriminate primary degenerative dementia from major depressive disorder (depression). Arq Neuropsiquiatr 2004;62:44-50.

16. Besthorn C, Förstl H, Geiger-Kabisch C, Sattel H, Gasser T, Schreiter-Gasser U. EEG coherence in Alzheimer disease. Electroencephalogr Clin Neurophysiol 1994; 90:242-245.

17. Knott V, Mohr E, Mahoney C, llivitsky V. Electroencephalographic coherence in Alzheimer's disease: comparisons with a control group and population norms. J Geriatr Psychiatry Neurol 2000;13: 1-8.

18. Anghinah R, Kanda PA, Jorge MS, Lima EE, Pascuzzi L, Melo AC. Alpha band coherence analysis of EEG in healthy adult's and Alzheimer's type dementia patients. Arq Neurospiquiatr 2000;58:272-275.

19. Adler G, Brassen S, Jajcevic J. EEG coherence in Alzheimer's dementia. J Neural Transm 2003;110:1051-1058.

20. Bartus RT, Dean III RL, Beer B, Lippa AS. The cholinergic hypothesis of geriatric memory dysfunction. Science 1982;217:408-414.

21. Fonseca LC. Demência: eletroencefalograma e eletroencefalograma quantitativo. In: Diretrizes da Associação Médica Brasileira e Conselho Federal de Medicina. Associação Médica Brasileira 2002:195-202.

22. Coben LA, Chi D, Snyder AZ, Storandt M. Replication of a study of a frequency analysis of the resting awake EEG in mild probable Alzheimer's disease. Electroencephalogr Clin Neurophysiol 1990;75:148-154.

23. Besthorn C, Zerfass R, Geiger-Kabisch C, et al. Discrimination of Alzheimer's disease and normal aging by EEG data. Electroencephalogr Clin Neurophysiol 1997;103:241-248.

24. Huang C, Wahlund L-O, Dierks T, Julin P, Winblad B, Jelic V. Discrimination of Alzheimer's disease and mild cognitive impairment by equivalent EEG sources: a cross-sectional and longitudinal study. Clin Neurophysiol 2000;111:1961-1967

25. Ihl R, Brinkmeyer J, Janner M, Kerdar MS. A comparison of ADAS and EEG in the discrimination of patients with dementia of the Alzheimer type from healthy controls. Neuropsychobiology 2000;41:102-107.

26. Anderer P, Saletu B, Kloppel B, Semlitsch HV, Werner H. Discrimination between demented patients and normals based on topographic EEG slow wave activity: comparison between statistics, discriminant analysis and artificial neural network classifiers. Electroencephalogr Clin Neurophysiol 1994;91:108-117.

27. Duffy FH, McAnulty GB, Albert MS. Temporoparietal electrophysiological differences characterize patients with Alzheimer's disease: a split-half replication study. Cereb Cortex 1995;5:215-221.

28. Strijers RL, Scheltens P, Jonkman EJ, de Rijke W, Hooijer C, Jonker C. Diagnosing Alzheimer's disease in community-dwelling elderly: a comparison of EEG and MRI. Dementia 1997;8:198-202.

29. Stevens A, Kircher T, Nickola M, Bartels M, Rosellen N, Wormstall H. Dynamic regulation of EEG power and coherence is lost early and globally in probable DAT. Eur Arch Psychiatry Clin Neurosci 2001;251:199-204.

30. Lehmann C, Koenig T, Jelic V, et al. Application and comparison of classification algorithms for recognition of Alzheimer's disease in electrical brain activity (EEG). J Neurosci Methods 2007;161:342-350. 